\title{
Time in e-Learning Research: A Qualitative Review of the Empirical Consideration of Time in Research into e-Learning
}

\author{
Elena Barbera ${ }^{1}$ and Marc Clarà ${ }^{2}$ \\ ${ }^{1}$ E-learn Center, Universitat Oberta de Catalunya (UOC), Roc Boronat 117, 6th Floor, 08018 Barcelona, Spain \\ ${ }^{2}$ Department of Developmental and Educational Psychology, University of Barcelona, Passeig de la Vall d'Hebron 171, \\ 08035 Barcelona, Spain
}

Correspondence should be addressed to Marc Clarà, marc.clara@gmail.com

Received 8 December 2011; Accepted 3 January 2012

Academic Editor: K. Capps

Copyright (C) 2012 E. Barbera and M. Clarà. This is an open access article distributed under the Creative Commons Attribution License, which permits unrestricted use, distribution, and reproduction in any medium, provided the original work is properly cited.

Time has been argued by several influential approaches as essential for understanding learning and teaching processes. In elearning, however, the traditional time limits of such processes are modified, which implies challenges and possibilities for elearning research. This paper is aimed at understanding how time is included in empirical e-learning research literature. With this aim in mind, the paper presents a qualitative review of 24 e-learning papers. Five issues are analysed: the conception of time, its inclusion in an explicative model, its inclusion in the research process, the analytical units, and the data used in the study of time. Based on our analysis, we discuss some implications and potentialities for e-learning research on the relations between time and learning.

\section{Introduction}

Time is such a ubiquitous factor of all human activity that sometimes it becomes invisible. This also happens with other omnipresent phenomena such as the atmosphere: sometimes we do not realise it is there; however, the atmosphere is crucial for understanding the Earth's physical phenomena. Similarly, time is absolutely crucial for understanding human activity, and especially, for comprehending educational phenomena.

The inclusion of time in the conceptualisation of educational phenomena is not something new. Ebbinhause, for example, already observed in 1885 what was called the "spacing effect" [1], according to which, given an amount of study time, spacing and distributing sessions over time promotes better learning than compressing them. Another example is Thurstone, who in the 1930s stated a relation, by means of a function, between the length of a list of paired associates and the time (number of trials) needed for memorising this list [2]. However, in our view, three 20th century fundamental approaches deserve particular mention for their contribution to and influence on the inclusion of time as an essential element in the understanding of learning. The first one is Carroll's model of school learning, in which the main variables of learning are expressed in terms of time. Thus, "aptitude" is expressed as "the amount of time that a student would need to learn something to a specified criterion," assuming optimal motivational and instructional conditions; motivation, which is called by Carroll "perseverance", is expressed as "the amount of time that a student would be willing to engage in active learning;" instruction, which Carroll calls "opportunity to learn," is expressed as "the amount of time that the organisation of a course, or other circumstances, would allow for learning" [3]. The main idea is that when the time spent by a student in active learning engagement is similar to the time needed by this student to learn in this environment, learning is optimal; when there is an important difference between these times, it can be reduced in order to optimise learning by modifying some of the variables. These two ideas from Carroll's model - that is, the idea of the time expression of learning and the idea of the difference between time spent in learning and time needed for learning as an explanation of the degree of learning - have been extremely influential in all 
spheres of the educational field, and they have also been the basis for a number of more recent models of learning [4-9].

A second highly influential conceptualisation of learning in relation to time was proposed by Skinner, who constructed a development of behaviourism which was called operant conditioning [10]. The main idea of operant conditioning is the association of an act to a stimulus that is lived as its consequence, and which reinforces the act. This association has as a result the repetition of the act. Learning is understood as changes in behaviour, so teaching is defined as "the arrangement of contingencies of reinforcement under which students learn" (P.64-65). In this theoretical scheme consisting of act-reinforcer, time is essential in both sides of the scheme. On the act side, Skinner does not only consider which act is to be reinforced, but the act in its proper moment. On the reinforcer side, Skinner extensively considers the moment the reinforcer is administered-immediate-and the schedules of reinforcements. The influence of behaviourism in general and of Skinner's behaviourism in particular in education is undeniable: although being theoretically widely discussed as an oversimplification of the learning process, the actreinforcer scheme is in practice broadly used nowadays in most educational settings and it has been the starting point for some current cognitivist psychological developments (see; ).

A third important view that considers time from the very essence of educational phenomena is mainly represented by two exceptionally influential approaches to learning and development: the proposals of Piaget and Vygotsky (see, e.g., $[14,15])$. Although the proposals of these two psychologists are quite different and contradictory in some points, they do share common key ideas. One of these ideas is the genetic approach to phenomena; that is, not only the consideration of the phenomenon from a phenotypic view-namely, its static expression in a specific moment-but also from a genetic (a developmental) view. In other words, one of the fundamental premises of these proposals is to consider the phenomenon as always in development; understanding a phenomenon is only possible if one understands where the present nature of the phenomenon comes from in the past and where the phenomenon goes toward in the future. The ideas of Vygotsky and Piaget are still strongly alive, and the genetic approach also remains present in almost all the constructivist developments based on one of these authors, or on both (see e.g., [16-20]). We highlight these three strongly influential conceptualisations of time in relation to learning because, to our mind, they represent the main different traditions which led us to what we currently more or less know about the role of time in learning phenomena. Our argument will by no means lead to proposing the integration of these traditions, and neither will we try to propose a new conceptualisation of the relation between time and learning which supersedes the conceptualisations of these three traditions. Instead, we want to suggest that for a number of decades now, genuinely new temporal conditions in learning phenomena have existed, and this fact permits us to develop all of these three traditions and to improve our understanding of the role of time in learning phenomena. These new temporal conditions of learning are a direct consequence of the development and proliferation of digital technologies, which have deeply transformed all human activity [21]. In the educational field, this transformation has given way to what is called e-learning: namely, learning mediated by computer or other digital technologies. According to Harasim [22], the mediation of such technologies transforms the very nature of educational processes and implies a shift of paradigm towards what this author calls "online education." What is crucial in Harasim's proposals is that online education is not a modality of education-as are faceto-face or distance education. Instead, it constitutes a new domain of learning - that is, a transformation of the nature of educational processes - which is being incorporated into both face-to-face and distance modalities of education. Harasim identifies five crucial aspects of the nature of the educational processes, which are transformed by the mediation of digital technologies; in this new domain, educational processes become (1) many to many (group communicationnetwork), (2) any place (place independent), (3) any time (time independent), (4) text-based (enhanced by multiple media), and (5) computer mediated.

The transformation of time limits, therefore, is one of the consequences of the irruption of digital technologies in educational processes. According to Harasim ([22], P.50), the expansion of these time limits means (1) $24 \mathrm{~h}$ access, all week, (2) that users can either respond immediately or can take time for reflection on the response, (3) that users can take all the time they need to prepare their contribution, and (4) that users can participate at their best readiness time.

So, from this starting point, what we have in mind is an opportunity to investigate the relationship between time and learning by considering time conditions, which were not possible before the advent of digital technologies. As we see it, this is an opportunity to push forward what we already know about this relationship, which is conceptualised differently depending on the theoretical and research tradition (we have briefly outlined the three main traditions above). The endeavour, therefore, implies doing research on learning mediated by digital technologies (e-learning) (This includes several different research fields, such as Computer-Supported Collaborative Learning (CSCL), Computer-Mediated Communication (CMC), and m-learning), which considers the relation between time and learning in some connection with any of these theoretical and research traditions on this issue.

This is the broad aim we have in mind when writing the present paper. However, in this paper, we only attempt to take an initial small step in order to make this endeavour possible. The argument is that, the endeavour we are suggesting necessarily implies the methodological incorporation of time into e-learning research. This is not an easy issue from a methodological point of view. Reimann [23], for example, stresses this difficulty and explores some methodological techniques in order to address this issue. In addition, in the specific field of e-learning, scholars deal with relatively new environments, and consequently, also with relatively new kinds of data. Besides, as several authors point out (e.g., [24-26]), e-learning research sometimes presents some lack of construct/content validity which may concern, among 
others, the theoretical construct of "time" (for further elaboration of this problem, see [27]).

This paper aims to contribute to addressing some methodological problems of the inclusion of time in empirical e-learning research by offering a picture of how it is done in empirical literature in this field.

We believe that this picture represents a very first step towards making a broader endeavour possible, one which is able to push forward our understanding of the relation between time and learning by investigating this issue under new time conditions.

According to this proposal, the organisation of this paper will proceed as follows: after presenting the method of this study, in Section 3 we will present a qualitative review of 24 research papers on e-learning, which consider time, and we analyse the concept of time they use, the type of explicative model into which time is incorporated, the phase of research in which time is included, and the units and data used for the analysis of time. In Section 4 we will discuss this picture in the light of the potentialities and limitations, it offers, for advancing our understanding of the relationship between time and learning.

\section{Method}

2.1. Selection of Papers. The selection of papers was carried out in three phases. In the first phase, framework phase, we used the ERIC database (Education Resources Information Center) to identify current papers related to e-learning published during 2006-2009. ERIC was used because of its significance in the educational field [28]. The search was focused around basic ERIC descriptors (BT) regarding learning and ICT in education (Learning, Technology Uses in Education). In order to delimit the search, these descriptors were combined with a number of other related secondary descriptors (RTs) (The RTs used were Electronic Classrooms, Handheld Devices, Interactive Video, Internet, Learner Controlled Instruction, Learning Laboratories, Assistive Technology, Multimedia Instruction, Audiovisual Instruction, Online Courses, Blended Learning, Protocol Materials, Computer Assisted Instruction, Teaching Machines, Computer Centers, Telecourses, Computer-Mediated Communication, Virtual Classrooms, Computer Software, Virtual Universities, Computers, Web-Based Instruction, Courseware, Distance Education, Educational Technology.) From this search we obtained 8511 e-learning papers. This broad search was designed to guarantee the inclusion of significant research approaches in the field in order to ensure that a proper knowledge framework for placing subsequent filters could be created.

In the second phase-time-centred phase-we refined the search by introducing several time descriptors in order to select those papers which considered time in any way. At that point, we looked for several broad temporal key words—such as time, pace, rhythm, phase, timeless, speed, and schedule, as well as progression, sequence, duration, and in the title, abstract or descriptors of papers. This selection process was complex mainly because of the contextual and polysemic nature of terms related with time. Sometimes those terms were used in a general way without contributing any different meanings to the research questions and units ("from a long time ago," "it is no time for," etc.). Furthermore, on other occasions, the terms were related to a global description needed in one part of the paper (e.g., in a data gathering explanation: a ten-week course). We also took a general decision about papers that include terminology regarding synchrony-asynchrony: we rejected the papers which used these terms only as a global framework or as a common label without addressing the implications of synchronic or asynchronic communication for learning (e.g., collaborative learning in asynchronous environments, synchronous communication, amongst others). By doing so, we reduced the number to 878 papers, but the results were still too broad. Consequently, specific criteria were then applied by examining the titles and abstracts of the papers. We admitted explicitness and implicitness of the consideration of the time dimension. Specifically, for implicitness the following criteria were applied:

(1) when a central dimension of study that implies the consideration of time is used.

(2) when a methodological technique that includes the consideration of time is used.

(3) when the study includes the analysis of a technological tool that includes time in its functioning (e.g., a real-time simulator), or that changes the time conditions of the task (e.g., an asynchronous communication tool).

Using this procedure yielded 173 papers. At this point we began the third phase, time approached phase, in which we introduced more specific criteria regarding how the papers had to consider the time factor.

(1) We considered only papers that report an empirical study.

(2) We considered only papers that include time in the methodological infrastructure as something to analytically consider: time could be explicit or implicit in the methodological infrastructure, but it had to actually be considered in the analysis of results.

After this last screening, we were left with 24 papers. These criteria were chosen because our purpose was to know more about the inclusion of time in research, not only in theory or instructional and technological practice. For this reason we needed to work with empirical papers, which actually consider time empirically-that is, in the analysis of results; in Section 3. Interrater reliability was calculated on the inclusion of papers by using the Kappa statistic. In this study, the result of the interrater analysis was Kappa $=.79$ $(P<0.001)$. This measure was statistically significant.

2.2. Analysis Procedure. Once the 24 papers had been selected, we qualitatively analysed them by open coding according to grounded theory analytic logic [29]. We used this analytic procedure for two main reasons. Firstly, as we have argued in the previous section, digital technologies modify 
TABLE 1: Answers found in the review for the five guiding questions.

\begin{tabular}{|c|c|c|c|}
\hline Question & Answers found in the review & $\begin{array}{c}\text { \# of papers } \\
(n=24)\end{array}$ & $\%$ of papers \\
\hline \multirow{4}{*}{ Conceptualisation of time } & $\begin{array}{l}\text { Time as the while during which a phenomenon is taking } \\
\text { place }\end{array}$ & 10 & $41.7 \%$ \\
\hline & Time as the moment in which a phenomenon takes place & 3 & $12.5 \%$ \\
\hline & Time as the temporal distance between two phenomena & 8 & $33.3 \%$ \\
\hline & Time as the evolution of a phenomenon & 7 & $29.2 \%$ \\
\hline \multirow{2}{*}{$\begin{array}{l}\text { Introduction of time into } \\
\text { an explicative model }\end{array}$} & Variable-based model & 20 & $83.3 \%$ \\
\hline & Model of a process & 4 & $16.7 \%$ \\
\hline \multirow{2}{*}{$\begin{array}{l}\text { Introduction of time into } \\
\text { the research process }\end{array}$} & $\begin{array}{l}\text { Introduction into the phase of defining dimensions and } \\
\text { variables }\end{array}$ & 23 & $95.8 \%$ \\
\hline & Introduction into the analytic phase & 3 & $12.5 \%$ \\
\hline \multirow{3}{*}{$\begin{array}{l}\text { Units used for analysing } \\
\text { and measuring time }\end{array}$} & Units based on formal time & 15 & $62.5 \%$ \\
\hline & Units based on internal components of the setting & 10 & $41.7 \%$ \\
\hline & Theoretical-based units & 3 & $12.5 \%$ \\
\hline \multirow{5}{*}{ Data used for studying time } & Electronic log files & 12 & $50 \%$ \\
\hline & Questionnaires, surveys, and interviews & 6 & $25 \%$ \\
\hline & Learning process students' products & 1 & $4.2 \%$ \\
\hline & Institutional documents & 1 & $4.2 \%$ \\
\hline & Setting design & 10 & $41.7 \%$ \\
\hline
\end{tabular}

The categories in each question are not exclusive (indeed they are only exclusive in the second question); that is, one and the same approach can include, for example, two different ideas of time, can introduce time into both phases, can simultaneously use units of different nature, and can combine different kinds of data. For this reason, in each question, the frequencies of each of the categories do not total 24, and the percentages do not total 100.

the traditional time limits in learning. As a consequence, it may be possible that research into e-learning uses new conceptions of time, units of analysis, types of data, and so on, which might be only distantly related to the main traditional theoretical conceptualisations of time and learning. Secondly, as we pointed out in the last section, there can be a problem of lack of construct/content validity in the approaches, which mismatches the explicit theoretical postulates and the actual methodological decisions and results [24-26]. In addition, in the papers we reviewed, the theoretical conceptualisation of the relationships between time and learning was mainly implicit. For these reasons, we opted to conduct a data-driven analysis. Thus, we established the selected 24 papers as our data, and we formulated five generative questions for them.

(1) How is time conceptualised in relation to teaching and learning phenomena?

(2) How is time introduced into a theoretical explicative model of online teaching and learning?

(3) How is time operationalised and introduced into a research process?

(4) Which kinds of units are used for this operationalisation of time?

(5) Which types of data are useful for studying time?

From these five generative questions, we examined the data and established tentative categories, which were continually verified and reformulated in dialectic relation with the data. According to Grounded Theory logic, the establishment of these categories was fully data driven. In doing so, we continually compared the options (indicators) taken by the different papers in order to relate them to the constructed categories and at the same time we reformulated the categories in order to fit them to their correspondent indicators in the data. This procedure was carried out until we obtained a consistent system of categories responding to each generative question; that is, all of the specific responses in the data were properly conceptually gathered together by the constructed categories. This analysis was carried out by means of three interrelated and constant procedures: coding, memoing, and data collecting. Coding means constructing categories that respond to the observations in data; memoing means writing iterative interpretations about categories; data collecting means, in our specific analysis, iteratively considering different parts of data for coding and memoing. These three procedures dialectically involve each other: the data usually challenged our tentatively constructed categories and led us to modify coding or to add a category, this at the same time led us to complete or rethink previous interpretations of data, which could also lead us to again modify coding, and which in turn could lead us to contrast with other parts of data, and so on.

\section{Results}

We will organise the results according to the five guiding questions that we proposed in section 2. Table 1 summarises the answers found in the review for each guiding question, and Table 2 synthesises the characterisation of the reviewed literature according to these questions. 
TABLE 2: Characterisation of literature according to the five guiding questions.

\begin{tabular}{|c|c|c|c|c|c|}
\hline & \multicolumn{2}{|c|}{ Meaning of time } & \multicolumn{3}{|c|}{ Methodological incorporation of time } \\
\hline & Theoretical model & Conception of time & $\begin{array}{l}\text { Phase of } \\
\text { incorporation }\end{array}$ & Unit & Data \\
\hline $\begin{array}{l}\text { Amiel and Orey } \\
{[30]}\end{array}$ & Variable-based model & $\begin{array}{l}\text { While during which } \\
\text { a phenomenon is } \\
\text { taking place }\end{array}$ & Dimensions & Formal time unit & $\begin{array}{l}\text { Questionnaire-surveys- } \\
\text { interviews }\end{array}$ \\
\hline $\begin{array}{l}\text { Bannink and van } \\
\text { Dam [31] }\end{array}$ & Process model & $\begin{array}{l}\text { Evolution of a } \\
\text { phenomenon }\end{array}$ & Dimensions & $\begin{array}{l}\text { Theoretical-based } \\
\text { unit }\end{array}$ & $\begin{array}{l}\text { Log files } \\
\text { Products }\end{array}$ \\
\hline Y. Chen et al. [32] & Process model & $\begin{array}{l}\text { Evolution of a } \\
\text { phenomenon }\end{array}$ & Analysis & Formal time unit & Log files \\
\hline $\begin{array}{l}\text { D. T. Chen et al. } \\
\text { [33] }\end{array}$ & Variable-based model & $\begin{array}{l}\text { While during which } \\
\text { a phenomenon is } \\
\text { taking place }\end{array}$ & Dimensions & Not specified & Setting design \\
\hline Cotner et al. 12] & Variable-based model & $\begin{array}{l}\text { Distance between } \\
\text { two phenomena }\end{array}$ & Dimensions & $\begin{array}{l}\text { Unit based on } \\
\text { internal components } \\
\text { of the setting }\end{array}$ & Setting design \\
\hline \multirow{3}{*}{ Crooks et al. [34] } & & $\begin{array}{l}\text { Evolution of } \\
\text { aphenomenon }\end{array}$ & Analysis & Formal time unit & $\begin{array}{l}\text { Questionnaire-surveys- } \\
\text { interviews }\end{array}$ \\
\hline & Variable-based model & $\begin{array}{l}\text { Distance between } \\
\text { two phenomena }\end{array}$ & Dimensions & $\begin{array}{l}\text { Unit based on } \\
\text { internal components } \\
\text { of the setting }\end{array}$ & Setting design \\
\hline & & $\begin{array}{l}\text { While during which } \\
\text { a phenomenon is } \\
\text { taking place }\end{array}$ & Dimensions & Formal time unit & Log files \\
\hline Ely et al. [35] & Variable-based model & $\begin{array}{l}\text { While during which } \\
\text { a phenomenon is } \\
\text { taking place }\end{array}$ & Dimensions & Formal time unit & Setting design \\
\hline Frydenberg [36] & Variable-based model & $\begin{array}{l}\text { Moment in which } \\
\text { the phenomenon } \\
\text { takes place }\end{array}$ & Dimensions & $\begin{array}{l}\text { Unit based on } \\
\text { internal components } \\
\text { of the setting }\end{array}$ & Institutional documents \\
\hline \multirow{3}{*}{ Hrastinski [37] } & & $\begin{array}{l}\text { Evolution of a } \\
\text { phenomenon }\end{array}$ & Analysis & Formal time unit & \\
\hline & Variable-based model & $\begin{array}{l}\text { Distance between } \\
\text { two phenomena }\end{array}$ & Dimensions & $\begin{array}{l}\text { Unit based on } \\
\text { internal components } \\
\text { of the setting }\end{array}$ & Setting design \\
\hline & & $\begin{array}{l}\text { While during which } \\
\text { a phenomenon is } \\
\text { taking place }\end{array}$ & Dimensions & Formal time unit & $\begin{array}{l}\text { Questionnaire-surveys- } \\
\text { interviews }\end{array}$ \\
\hline Hrastinski [38] & Variable-based model & $\begin{array}{l}\text { Distance between } \\
\text { two phenomena }\end{array}$ & Dimensions & $\begin{array}{l}\text { Unit based on } \\
\text { internal components } \\
\text { of the setting }\end{array}$ & Setting design \\
\hline Hrastinski [28] & Variable-based model & $\begin{array}{l}\text { Distance between } \\
\text { two phenomena }\end{array}$ & Dimensions & $\begin{array}{l}\text { Unit based on } \\
\text { internal components } \\
\text { of the setting }\end{array}$ & Setting design \\
\hline $\begin{array}{l}\text { Jeong and Frazier } \\
\text { [39] }\end{array}$ & Variable-based model & $\begin{array}{l}\text { Moment in which } \\
\text { the phenomenon } \\
\text { takes place }\end{array}$ & Dimensions & Formal time unit & Log files \\
\hline Kapur et al. [40] & Variable based model & $\begin{array}{l}\text { Evolution of a } \\
\text { phenomenon }\end{array}$ & Dimensions & $\begin{array}{l}\text { Unit based on } \\
\text { internal components } \\
\text { of the setting }\end{array}$ & Log files \\
\hline $\begin{array}{l}\text { Kim and Keller } \\
{[41]}\end{array}$ & Variable-based model & $\begin{array}{l}\text { While during which } \\
\text { a phenomenon is } \\
\text { taking place }\end{array}$ & Dimensions & Formal time unit & $\begin{array}{l}\text { Questionnaire-surveys- } \\
\text { interviews }\end{array}$ \\
\hline Kevin et al. [42] & Variable-based model & $\begin{array}{l}\text { While during which } \\
\text { a phenomenon is } \\
\text { taking place }\end{array}$ & Dimensions & Formal time unit & Log files \\
\hline
\end{tabular}


TABle 2: Continued.

\begin{tabular}{|c|c|c|c|c|c|}
\hline & \multicolumn{2}{|c|}{ Meaning of time } & \multicolumn{3}{|c|}{ Methodological incorporation of time } \\
\hline & Theoretical model & Conception of time & $\begin{array}{l}\text { Phase of } \\
\text { incorporation }\end{array}$ & Unit & Data \\
\hline Krause et al. [43] & Variable-based model & $\begin{array}{l}\text { While during which } \\
\text { a phenomenon is } \\
\text { taking place }\end{array}$ & Dimensions & Formal time unit & Log files \\
\hline $\begin{array}{l}\text { Martin and Klein } \\
{[44]}\end{array}$ & Variable-based model & $\begin{array}{l}\text { While during which } \\
\text { a phenomenon is } \\
\text { taking place }\end{array}$ & Dimensions & Formal time unit & Log files \\
\hline Metz [45] & Variable-based model & $\begin{array}{l}\text { Moment in which } \\
\text { the phenomenon } \\
\text { takes place }\end{array}$ & Dimensions & Formal time unit & Log files \\
\hline Offir et al. [46] & Variable-based model & $\begin{array}{l}\text { Distance between } \\
\text { two phenomena }\end{array}$ & Dimensions & $\begin{array}{l}\text { Unit based on } \\
\text { internal components } \\
\text { of the setting }\end{array}$ & Setting design \\
\hline $\begin{array}{l}\text { Osman and } \\
\text { Herring [47] }\end{array}$ & Process model & $\begin{array}{l}\text { Evolution of a } \\
\text { phenomenon }\end{array}$ & Dimensions & $\begin{array}{l}\text { Theoretical-based } \\
\text { unit }\end{array}$ & Log files \\
\hline $\begin{array}{l}\text { Papadopoulos et al. } \\
\text { [48] }\end{array}$ & 1. Variable-based model & $\begin{array}{l}\text { While during which } \\
\text { a phenomenon is } \\
\text { taking place }\end{array}$ & Dimensions & Formal time unit & Log files \\
\hline Roblyer et al. [49] & Variable-based model & $\begin{array}{l}\text { Distance between } \\
\text { two phenomena }\end{array}$ & Dimensions & $\begin{array}{l}\text { Unit based on } \\
\text { internal components } \\
\text { of the setting }\end{array}$ & Setting design \\
\hline Skylar [50] & Variable-based model & $\begin{array}{l}\text { Distance between } \\
\text { two phenomena }\end{array}$ & Dimensions & $\begin{array}{l}\text { Unit based on } \\
\text { internal components } \\
\text { of the setting }\end{array}$ & Setting design \\
\hline $\begin{array}{l}\text { Yoon and Johnson } \\
\text { [51] }\end{array}$ & Process model & $\begin{array}{l}\text { Evolution of a } \\
\text { phenomenon }\end{array}$ & Dimensions & $\begin{array}{l}\text { Theoretical-based } \\
\text { unit }\end{array}$ & Log files \\
\hline & & & & & $\begin{array}{l}\text { Questionnaire-surveys- } \\
\text { interviews }\end{array}$ \\
\hline
\end{tabular}

3.1. How Is Time Conceptualised in relation to Teaching and Learning Phenomena? Time can be used in literature with several different meanings, and it is crucial to distinguish between them in order to know what is actually being studied behind the label of "time." In our review, we have basically found four different ideas of time. First of all, in 10 of the 24 studies (see Tables 1 and 2), time is understood as "the while during which a phenomenon is taking place." Examples of this conception can be found in Ely et al. [35], who, from the field of training environments design, consider how much time trainees invest in the training environment. These authors, moreover, use this conception of time as an indicator of the trainees' effort. Another example is the approach of Papadopoulos et al. [48], who, from the field of question prompting, consider the amount of time students spend on the learning task. This idea of time is the most widely used in the reviewed literature, as can be seen in Table 1.

Another conception of time used in the reviewed literature ( 3 studies out of 24) is the understanding of time as "the moment in which a phenomenon takes place." This conception is clearly different from the previous one; in that case the aim was to count how much time the phenomenon lasts, while from this conception of time, the idea is to situate the phenomenon temporally. Examples of this last conception are found in Metz [45], who works in the field of online quizzes and studies the moment in which the students access the quiz. Other clear examples can be found in Jeong and Frazier [39], who are interested in when students write more influential postings in a discussion, and in Frydenberg [36], who studies the moment in which students drop out.

A third conception of time we have found widely in the data (8 studies out of 24) is the understanding of time as "the temporal space between two phenomena." In other words, what is studied with this conception is how much time passes between one phenomenon finishing and another phenomenon taking place; for example, from when one participant completes an action until another participant carries out another action. In e-learning literature, this conception is usually used when synchronicity-asynchronicity in conversations is studied: short versus long temporal space between conversational turns. Examples of this idea of time can be found in Hrastinski [28, 37], Roblyer et al. [49] and Offir et al. [46]. Another use of this same conception of time is found in Crooks et al. [34], who study the effect of the temporal contiguity between text and images in multimedia materials.

The forth conception of time found in our study (7 studies out of 24) is the understanding of time as "the evolution of a phenomenon." With this conception what is being studied is how a phenomenon changes over time. An example of 
this idea is the proposal of Kapur et al. [40], who study the evolution of the students' participation and the evolution of the type of interaction. Another example can be found in Yoon and Johnson [51], who study the evolution of work teams.

\subsection{How Is Time Introduced into a Theoretical Explicative} Model of Online Teaching and Learning? The four conceptions of time identified above can be included in an explicative model in two different basic ways: in a variable-based model or in a model of a process. When time is introduced into a variable-based model, it is taken as a variable, that is, it is isolated from the whole environment and relations with other isolated variables are sought. For example, Ely et al. [35] look for relations between "time invested in training" and "posttraining knowledge level." With another conception of time, Hranstinski [28] looks for relations between "synchronicity-asynchronicity," "Participation," and "type of exchanges" in the discussion. In these two examples, time can be considered as an independent variable, but there are also approaches that take time as a dependent variable. One example is Papadopoulos et al. [48], who look for relations between the "prompting mode" and the "time students spend on the learning task."

Nevertheless, time can also be introduced into a model not based on variables, but rather into a model which tries to explain a process [23]. When time is introduced into a model of a process, it is taken as an intrinsic part of the process; it is not isolated from the other aspects of the studied phenomena, but interwoven with them. For example, Y. Chen et al. [32] take the construction of knowledge as a process and analyse it by means of different dimensions. The authors are interested in how the frequency of categories from dimensions changes over time. Another example is the approach of Yoon and Johnson [51], who study the life of work teams as a process and try to describe their evolution (time as evolution of a phenomenon).

In our data, the majority of studies, as many as 20 out of 24 , adopted a variable-based model, while only 4 studies adopted a model of a process.

\subsection{How Is Time Operationalised and Introduced into a} Research Process? Once we become aware of the conception of time and of how this conception is integrated into an explicative model, it is then necessary to understand how it can be translated into the actual research process. According to the reviewed literature, this incorporation of time into research can take place in two different phases of the process: the phase of establishing and defining dimensions and variables and the phase of analysis.

The incorporation of time via dimensions and variables means that the conception of time included in the explicative model is operationalised into a dimension (if it comes from a model of a process) or into a variable (if it comes from a variable-based model). From a variable-based model, we can find, for example, the approach of Kapur et al. [40], where the "patterns of evolution of Participation and Interaction" are taken as variables with different values, and they are statistically related to the "group performance," also taken as a variable with different values. In a similar way, Jeong and Frazier [39] take "the moment in which participants write postings" as a variable, with three values-early in the week, midweek, weekend-and relate them statistically to the "number of responses to the postings."

From a process model, this operationalisation is done using dimensions of analysis, which take the time conception from the explicative model. For example, Osman and Herring [47], who consider time as the evolution of the construction of knowledge, use an operationalisation of the idea of construction of knowledge proposed by Gunawardena, Lowe and Anderson [52], which enables such a construction to be characterised by means of five phases that take place throughout the process. Similarly, Yoon and Johnson [51] try to characterise the "evolution of teams" by means of seven phases that the authors construct from data and from two preexisting operationalisations (coding schemes) of the dimension.

However, some approaches do not incorporate time via dimensions or variables, but only in the analytic phase, via elaboration of results. Incorporating time via the elaboration of results in the analytic phase means taking a dimension or variable that does not necessarily include time and considering its values in different periods of time. For example, Cotner et al. [53] take the variable "participation," which does not include time-participation and is calculated as the number of questions answered by students in a quiz. In the analytical phase, however, the authors calculate participation in three different moments of the semester-beginning, middle, end of the semester. In this example, therefore, time as "the evolution of a phenomenon" is incorporated, not via variables, but via the elaboration of results in the analytic phase. This is also done in process model approaches. For example, Y. Chen et al. [32] characterise the construction of knowledge by means of Guan, Tsai, and Hwang [54] modification of Henry's coding scheme's. This coding scheme considers four dimensions: participation rate, social cues, interaction types, and cognitive-metacognitive skills. None of these dimensions include time. However, in the analytic phase, the authors establish four periods of time in the discussions, and look at which values the four dimensions take in each period. Again, time is not incorporated here via the dimensions, but in the analytic phase.

Several conceptions of time can be incorporated by the same approach, and this can be done in both phases of the research process. For example, in Cotner et al. [53], time as temporal distance between phenomena is incorporated via variables, by considering automated immediate checking of student tests as an independent variable. Moreover, in the analytic phase, time as the evolution of a phenomenon is also incorporated by calculating the students' participation in different periods of time. In this example, then, one conception of time is included via variables, and another conception of time is included in the analysis phase. Nevertheless, it is also possible to include more than one conception of time in the same phase of the research process. This can be seen, for example, in Hrastinski [37]. This author establishes, on the one hand, a variable (independent) that is "synchronousasynchronous communication" (time as temporal distance 
between phenomena), and on the other hand, a variable (dependent) that is the "number of hours students spend on interpersonal interaction and working with content" (time as the while during which a phenomenon is taking place). Similarly, Crooks et al. [34] also establish as an independent variable "the temporal contiguity between text and images in multimedia materials" (temporal distance between phenomena) and "the time spent by student on task" as a dependent variable. In these last examples, therefore, there are two conceptions of time included in the variables phases, one of them as an independent variable and the other as a dependent variable. As can be seen in Table 1, in the reviewed studies, the inclusion of time in the research process took place mainly via dimensions variables (23 out of 24 studies). Three studies included time in the analytic phase, but two of them had also included time previously in the definition of variables dimensions.

3.4. Which Kinds of Units Are Used for This Operationalisation of Time? Once we have seen how time is incorporated into the research process, the question that then arises is how time is measured. In our paper, we have found three kinds of units, which permit time to be measured and analysed: units based on formal time, units based on internal components of the setting, and units based on theoretical models.

By units based on formal time, we refer to commonly established time measurements, such, minutes, hours, days, weeks, and months. Examples of use of these kinds of units can be found in Krause et al. [43], minutes, Metz [45], hours, or Ely et al. [35], days. There are also approaches which do not directly use these units, but units based on them. For example, Y. Chen et al. [32] use "periods of 20 minutes" as a unit, and Jeong and Frazier [39] use "periods of 2 days".

Another option is to use units based on internal components of the setting. These kinds of units take as their time references the idiosyncratic and defining elements of the setting itself. For example, in Hrastinski [28, 37], one temporal unit is the whole course, which can take two values: synchronous and asynchronous. The unit, in this case, is defined by the specific configuration of the setting. Quite a different unit based on internal components of the setting is used by Kapur et al. [40]. These authors take as a temporal unit the "utterance" in the discussion. By considering the order of utterances in the discussion, they take the utterances as "ticks on the evolutionary clock" (P. 57). As can be seen, utterances are idiosyncratic of each discussion: the time marked by utterances is in a time scale which only pertains to "that" specific discussion.

Finally, several approaches use theoretical-based units. These units are based on any theoretical statement according to which when determined indicators appear in data there is a change of unit. This is used, for example, by Osman and Herring [47] whose units are the phases defined by Gunawardenaet al. [52] according to what participants do with meanings - that is, the nature of the actions of participants toward knowledge. Similarly, but from other defining criteria, also Yoon and Johnson [51] use phases defined according to the state of the task participants are working on.
In the studies reviewed, the most commonly used units are units based on formal time (15 studies) and units based on internal components of the setting (10 studies), which in some instances (4 studies) are combined-see Table 2. Theoretical-based units are much less commonly used (3 studies).

\subsection{Which Type of Data Is Useful for Studying Time? After} examining the units and measurements used for studying time, what remains unaddressed is what type of data is useful for measuring and analysing time. In our paper, we have basically found five types of data which different approaches use for doing so: electronic log files, questionnaires, surveys, interviews, learning process products, institutional documents, and the setting design.

Electronic $\log$ files permit the time dimension of the online activity to be registered and conserved, that is, the analyst can recover the online activity in time. These log files can consist of the participants' entries to the online environment (e.g., [45]), the complete contributions made by the participants in a discussion (e.g., [40, 47]) data about responses between participants (e.g., [39]) and so on.

Other approaches use data produced in the direct interaction between the researcher and the participants by means of questionnaires, surveys, or interviews. For example, Kim and Keller [41], by means of weekly questionnaires, ask the participants how much time they have spent studying the subject-note that this study time is not necessarily online, so in this case log files would not have been enough.

Another kind of data which can also be useful if properly timely situated in the process consists of the products which participants create as part of their learning process. We can find an example in Bannink and van Dam [31], who analyse a video selected by students and reflective texts written by them about this video. Both documents were designed as learning activities in the course.

Other data which can be useful in some specific approaches consists of institutional documents from the courses. For example, [36] uses this type of data for studying student dropouts: when a student actively dropped out of the course, he/she had to request their withdrawal in the student services office; thus, the information generated there was useful for knowing the moment these withdrawals occurred (p.8).

Finally, some measures of time are not taken from data gathered with this aim, but just experimentally adopted as part of the setting design. This is especially clear in studies which take as an independent variable the "synchronousasynchronous configuration of the discussion." In these cases, the value of this variable is chosen by the researcher; it is pre-defined in order to test its effect. Examples of this option can be found in Roblyer et al. [49] and Offir et al. [46]. However, the "synchronous-asynchronous configuration of discussions" is not the only variable which can be decided from the setting design. Ely et al. [35], for example, manipulate and predecide the variable "number of days of training"; D. T. Chen et al. [33] manipulate different variables of the pedagogic design, among them the duration of students' discussion.

Obviously, these different types of data can be combined for measuring time in the same approach. For example, [37] 
decides the values of time as distance between two phenomena (synchronous-asynchronous configurations) in the setting design and then the author measures time as the while during which a phenomenon is taking place (study time) in questionnaires and interview data. Moreover, different data can also be used at the same time for measuring the same conception of time. We can find this option in Yoon, and Johnson [51], who study the evolution of teams by combining $\log$ files and survey data. A similar approach is taken by Bannink and Van Dam [31], who combine log files and learning process products data in order to study the evolution of inquiry.

The studies included in this revision mainly used log files (12 studies) and the setting design (10 studies) as data for analysing time, followed by questionnaires-surveysinterviews (6 studies). Setting design and $\log$ files are combined in one study [34], and setting design and questionnaires-surveys-interviews are combined in three studies. The other types of data are much less common-one study uses learning process products, in combination with log files [31], and one study uses institutional documents [36].

\section{Discussion and Conclusions}

As stated in the first section, in writing this paper we had two aims in mind. The immediate problem this paper addresses is the methodological inclusion of time in empirical e-learning research. However, in our approach, this methodological problem must be seen as a part of a broader aim, namely, advancing our understanding of the relations between time and learning by doing research on this issue with new time conditions that permit the enrichment and development of existing conceptualisations of such relationships. In the last section, we presented a picture of how the selected empirical literature on e-learning solves the immediate methodological problem of the inclusion of time in e-learning research. In this discussion, we will examine how this picture has implications for our more general aim and, therefore, in which directions it should be developed towards this aim.

From this point of view, the first relevant aspect of our results is that the methodological problem of including time in empirical e-learning research is addressed by a small proportion of the literature we examined. It is necessary to be very cautious on this point because of the limitations of our paper selection procedure. However, according to our operationalisation, we only found 24 papers that empirically considered time in their analysis. No further discussion is needed on this point: obviously, if time is not included in empirical research, no empirical data will be available on the relations between time and learning, so the existing conceptualisations about time and learning will hardly be challenged and enriched.

Another relevant issue of the picture drawn in the last section, from the point of view of our broader aim, is the connection-or lack of connection-between the empirical approaches which include time and any well-articulated previous conceptualisation of the relations between time and learning. As we mentioned in the first section, the theoretical postulates about the relations between time and learning were mainly implicit in the papers that we reviewed. However, the connection could also be implicit. In our analysis, we identified four conceptions of time, and if we examine the implicit connection between these conceptions and the existing main conceptualisations of the relations between time and learning, we could say that implicit connections can be seen but only on a superficial level. For example, studies that consider "time as the while during which a phenomenon is taking place" address the relation between time and learning by means of the expression of learning (or variables involved in learning) in terms of time, which, as we saw, is essentially the same basic operation that lies behind Carroll's model and its developments. This, however, does not mean that these studies assume the other aspects of Carroll's model. Something similar happens with the conception of "time as the evolution of a phenomenon", in which there is the idea that learning (or its variables or dimensions) is a phenomenon that changes and evolves over time; the same general idea as in the genetic approaches. Again, however, the studies cannot be associated to a specific articulation of time and learning, but only to this general genetic idea. In the studies that consider the conception of "time as the moment in which a phenomenon takes place," there is the idea that the effect of an action or phenomenon and its implications on learning (or its variables) varies according to the moment in which this action or phenomenon takes place. This idea is somewhat similar to Skinner's emphasis on the specific moment in which acts and reinforcements take place. However, the other aspects of Skinner's conceptualisation are not taken on board by such studies.

If there is not a substantive connection, even an implicit one, between empirical research and any well-articulated conceptualisation of the relations between time and learning, the reconstruction, challenging, and enrichment of the understanding of these relations will hardly be possible, because it will be very difficult to situate the empirical results theoretically. According to our analysis, these connections are not substantive, but only superficial. This fact, in our view, seriously hinders improving our understanding of the relations between time and learning.

A third relevant issue uncovered by our results is the presence or absence, in the methodological incorporation of time in current empirical research on e-learning, of ideas, methods, or resources which are potentially capable of challenging and enriching the existing understanding of the relations between time and learning. According to our analysis, these potentialities do exist in empirical research. The first potentially challenging-enriching idea is the broad incorporation into empirical research of the conception of "time as the temporal distance between two phenomena." In this conception, there is the idea that the rhythm of different phenomena, and especially the rhythm of interaction, has implications for learning (or its variables). The growing interest in this idea is clearly related to the mediation of digital technologies, which permit a great range of interaction rhythms between face-toface synchronicity and traditional epistolary asynchronicity. As far as we know, the relationship between the different possible rhythms of interaction (or other phenomena) and learning (or their variables) is not yet conceptualised in any 
articulated learning theory. A second potentially enriching issue is the use of the conception of "time as the moment in which a phenomenon takes place" in e-learning time limits. This idea, as we saw, is superficially related to Skinner's conceptualisation. When this conception is used in e-learning time limits, the "possible moments" are expanded to $24 \mathrm{~h}$ a day, 7 days a week. If this idea in empirical e-learning research was more substantially connected to Skinner's proposals, or its later developments, the e-learning expansion of time limits could clearly enrich Skinner's conceptualisation. A third potentially enriching resource we find in empirical e-learning research is the possibility of predesigning the temporal conditions of interactions without creating an artificial setting. This can permit great flexibility in testing or empirically developing theoretical ideas about the relations between time and learning. A fourth potentially enriching resource is the use of $\log$ files as data for analysis, since they allow the whole online interaction in time to be gathered and recovered, thus providing much richer data for analysis.

Despite the contributions the present study may have made, it does also have some limitations which must be kept in mind. Although the selection procedure has been systematic, and based on specific criteria, the paper is obviously not complete. We based the study on the ERIC database because of its significance in the educational field, but of course there are many others and some approaches may have been missed. Nevertheless, we believe that the first small step we have attempted to take in this paper is an important one, because it is necessary in order to take the following steps towards a better understanding of the relation between time and learning.

\section{References}

[1] M. A. Gallo and M. Odu, "Examining the relationship between class scheduling and student achievement in college algebra," Community College Review, vol. 36, no. 4, pp. 299-325, 2009.

[2] S. E. Gathercole, Ed., Models of Short-Term Memory, Psychology Press, Hove, UK, 1996.

[3] J. B. Carroll, "The model of school learning: progress of an idea," in Time and School Learning, L. W. Anderson, Ed., pp. 15-45, Croom Helm, Kent, UK, 1984.

[4] S. N. Bennett, "Recent research on teaching: a dream, a belief, and a model," British Journal of Educational Psychology, vol. 48, pp. $127-147,1978$.

[5] B. S. Bloom, Human Characteristics and School Learning, McGraw-Hill, New York, NY, USA, 1976.

[6] G. Burt, "Media effectiveness, essentiality, and amount of study: a mathematical model," British Journal of Educational Technology, vol. 37, no. 1, pp. 121-130, 2006.

[7] W. W. Cooley and G. Leinhardt, The Application of a Model for Investigating Classroom Processes, University of Pittsburgh, Learning Research \& Development Center, Pittsburgh, Pa, USA, 1975.

[8] A. Harnischfeger and D. E. Wiley, "The teaching learning process in elementary schools: a synoptic view," Curriculum Inquiry, vol. 6, no. 1, pp. 5-43, 1976.

[9] G. D. Haertel, H. J. Walberg, and T. Weinstein, "Psychological models of educational performance: a theoretical synthesis of constructs," Review of Educational Research, vol. 53, no. 1, pp. 75-91, 1983.
[10] B. F. Skinner, The Technology of Teaching, Meredith, New York, NY, USA, 1968.

[11] D. Leiser, "Constructivism, epistemology and information processing," Anuario de Psicología, vol. 69, pp. 93-114, 1996.

[12] M. J. Rodrigo, “¿Es compatible el constructivismo piagetiano con el del procesamiento de la información?" Anuario de Psicología, vol. 69, pp. 123-126, 1996.

[13] L. Shulman, "Paradigms and research programs in the study of teaching: a contemporary perspective," in Handbook of Research on Teaching, M. Wittrock, Ed., pp. 3-36, MacMillan, New York, NY, USA, 1986.

[14] J. Piaget, Six Psychological Studies, Harvester Press, Brighton, UK, 1980.

[15] L. S. Vygotsky, "The collected works of L.S. Vygotsky," in The History of the Development of Higher Mental Functions, R. W. Rieber, Ed., vol. 4, Plenum Press, New York, NY, USA, 1997.

[16] C. Coll, J. Onrubia, and T. Mauri, "Assisting learning in educational contexts: exerting educational influence and instruction analysis," Revista de Educación, vol. 364, pp. 33-70, 2008.

[17] Y. Engeström, "Expansive learning at work: toward an activity theoretical reconceptualization," Journal of Education and Work, vol. 14, no. 1, pp. 133-156, 2001.

[18] A. Karmiloff-Smith, Beyond Modularity, MIT Press, Cambridge, Mass, USA, 1992.

[19] N. Mercer, "The seeds of time: why classroom dialogue needs a temporal analysis," Journal of the Learning Sciences, vol. 17, no. 1, pp. 33-59, 2008.

[20] J. I. Pozo, Human Mind: The World, the Consciousness and the Body, Ediciones Morata S.L., Madrid, Spain, 2001.

[21] M. Castells, The Information Age: Economy, Society and Culture, vol. 1 of The Rise of the Network Society, Blackwell Publishing, Oxford, UK, 2nd edition, 2002.

[22] L. Harasim, "Shift happens: online education as a new paradigm in learning," Internet and Higher Education, vol. 3, no. 1-2, pp. 41-61, 2000.

[23] P. Reimann, "Time is precious: variable- and event-centred approaches to process analysis in CSCL research," International Journal of Computer-Supported Collaborative Learning, vol. 4, no. 3, pp. 239-257, 2009.

[24] B. de Wever, T. Schellens, M. Valcke, and H. van Keer, "Content analysis schemes to analyze transcripts of online asynchronous discussion groups: a review," Computers \& Education, vol. 46, no. 1, pp. 6-28, 2006.

[25] L. Rourke and T. Anderson, "Validity in quantitative content analysis," Educational Technology Research and Development, vol. 52, no. 1, pp. 5-18, 2004.

[26] A. Weinberger and F. Fischer, "A framework to analyze argumentative knowledge construction in computer-supported collaborative learning," Computers \& Education, vol. 46, no. 1, pp. 71-95, 2006.

[27] M. Clarà and T. Mauri, "Toward a dialectic relation between the results in CSCL: three critical methodological aspects of content analysis schemes," International Journal of ComputerSupported Collaborative Learning, vol. 5, no. 1, pp. 117-136, 2010.

[28] S. Hrastinski, "The potential of synchronous communication to enhance participation in online discussions: a case study of two e-learning courses," Information and Management, vol. 45, no. 7, pp. 499-506, 2008.

[29] A. L. Strauss and J. Corbin, Basics of Qualitative Research: Grounded Theory Procedures and Techniques: Qualitative Analysis for Social Scientists, SAGE, Newbury Park, Calif, USA, 1990. 
[30] T. Amiel and M. Orey, "Do you have the time? Investigating online classroom workload," Journal of Educational Technology Systems, vol. 35, no. 1, pp. 31-43, 2007.

[31] A. Bannink and J. van Dam, "Premature closure and guided reinvention: a case study in a web-based learning environment," Teachers and Teaching, vol. 13, no. 6, pp. 565-586, 2007.

[32] Y. Chen, N. S. Chen, and C. C. Tsai, "The use of online synchronous discussion for web-based professional development for teachers," Computers \& Education, vol. 53, no. 4, pp. 11551166, 2009.

[33] D. T. Chen, Y. M. Wang, and D. Hung, "A journey on refining rules for online discussion: implications for the design of learning management systems," Journal of Interactive Learning Research, vol. 20, no. 2, pp. 157-173, 2009.

[34] S. Crooks, D. White, S. Srinivasan, and Q. Wang, "Temporal, but not spatial, contiguity effects while studying an interactive geographic map," Journal of Educational Multimedia and Hypermedia, vol. 17, no. 2, pp. 145-169, 2008.

[35] K. Ely, T. Sitzmann, and C. Falkiewicz, "The influence of goal orientation dimensions on time to train in a self-paced training environment," Learning and Individual Differences, vol. 19, pp. 146-150, 2009.

[36] J. Frydenberg, "Persistence in university continuing education online classes," International Review of Research in Open and Distance Learning, vol. 8, no. 3, pp. 1-15, 2007.

[37] S. Hrastinski, "Introducing an informal synchronous medium in a distance learning course: how is participation affected?" Internet and Higher Education, vol. 9, no. 2, pp. 117-131, 2006.

[38] S. Hrastinski, "The relationship between adopting a synchronous medium and participation in online group work: an explorative study," Interactive Learning Environments, vol. 14, no. 2, pp. 137-152, 2006.

[39] A. Jeong and S. Frazier, "How day of posting affects level of critical discourse in asynchronous discussions and computersupported collaborative argumentation," British Journal of Educational Technology, vol. 39, no. 5, pp. 875-887, 2008.

[40] M. Kapur, J. Voiklis, and C. K. Kinzer, "Sensitivities to early exchange in synchronous computer-supported collaborative learning (CSCL) groups," Computers \& Education, vol. 51, no. 1, pp. 54-66, 2008.

[41] C. Kim and J. M. Keller, "Effects of motivational and volitional email messages (MVEM) with personal messages on undergraduate students' motivation, study habits and achievement," British Journal of Educational Technology, vol. 39, no. 1, pp. 3651, 2008.

[42] K. Kevin, C. Hollingsead, G. Fitzgerald et al., "Case-based instruction in different delivery contexts: the impact of time in cases," Journal of Interactive Learning Research, vol. 20, no. 4, pp. 445-467, 2009.

[43] U. M. Krause, R. Stark, and H. Mandl, "The effects of cooperative learning and feedback on e-learning in statistics," Learning and Instruction, vol. 19, no. 2, pp. 158-170, 2009.

[44] F. Martin and J. Klein, "Effects of objectives, practice, and review in multimedia instruction," Journal of Educational Multimedia and Hypermedia, vol. 17, no. 2, pp. 171-189, 2008.

[45] A. M. Metz, "The effect of access time on online quiz performance in large biology lecture courses," Biochemistry and Molecular Biology Education, vol. 36, no. 3, pp. 196-202, 2008.

[46] B. Offir, Y. Lev, and R. Bezalel, "Surface and deep learning processes in distance education: synchronous versus asynchronous systems," Computers \& Education, vol. 51, no. 3, pp. 1172-1183, 2008.
[47] G. Osman and S. C. Herring, "Interaction, facilitation, and deep learning in cross-cultural chat: a case study," Internet and Higher Education, vol. 10, no. 2, pp. 125-141, 2007.

[48] P. M. Papadopoulos, S. N. Demetriadis, I. G. Stamelos, and I. A. Tsoukalas, "Prompting students' context-generating cognitive activity in ill-structured domains: does the prompting mode affect learning?" Educational Technology Research and Development, vol. 57, no. 2, pp. 193-210, 2009.

[49] M. D. Roblyer, J. Freeman, M. B. Donaldson, and M. Maddox, "A comparison of outcomes of virtual school courses offered in synchronous and asynchronous formats," Internet and Higher Education, vol. 10, no. 4, pp. 261-268, 2007.

[50] A. A. Skylar, "A comparison of asynchronous online textbased lectures and synchronous interactive web conferencing lectures," Issues in Teacher Education, vol. 18, no. 2, pp. 69-84, 2009.

[51] S. W. Yoon and S. D. Johnson, "Phases and patterns of group development in virtual learning teams," Educational Technology Research and Development, vol. 56, no. 5-6, pp. 595-618, 2008.

[52] C. N. Gunawardena, C. A. Lowe, and T. Anderson, "Analysis of a global online debate and the development of an interaction analysis model for examining social construction of knowledge in computer conferencing," Journal of Educational Computing Research, vol. 17, no. 4, pp. 397-431, 1997.

[53] S. H. Cotner, B. A. Fall, S. M. Wick, J. D. Walker, and P. M. Baepler, "Rapid feedback assessment methods: can we improve engagement and preparation for exams in large-enrollment courses?" Journal of Science Education and Technology, vol. 17, no. 5, pp. 437-443, 2008.

[54] Y. H. Guan, C. C. Tsai, and F. K. Hwang, "Content analysis of online discussion on a senior-high-school discussion forum of a virtual physics laboratory," Instructional Science, vol. 34, no. 4, pp. 279-311, 2006. 

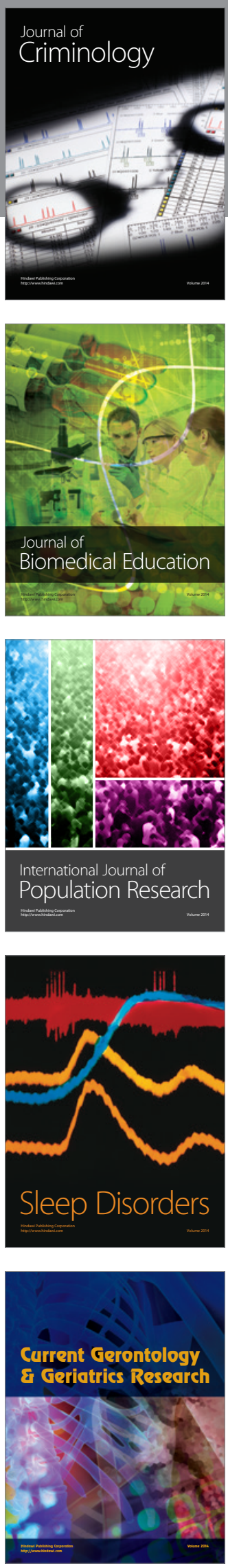
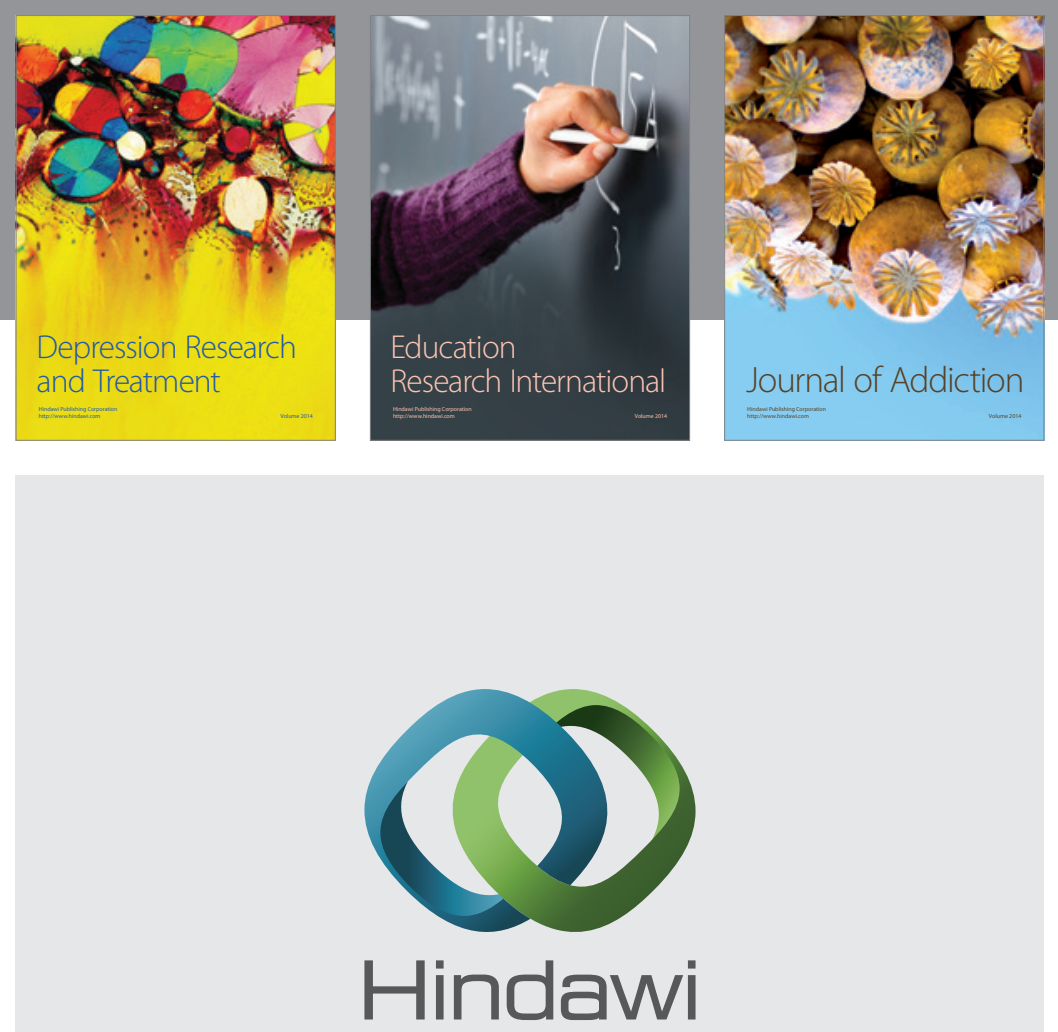

Submit your manuscripts at

http://www.hindawi.com

Child Development Research
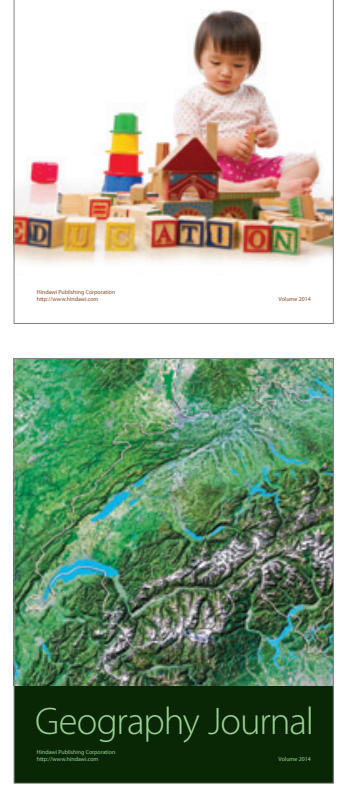

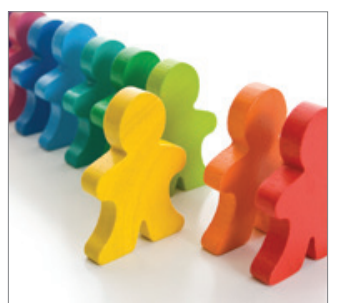

Autism

Research and Treatment
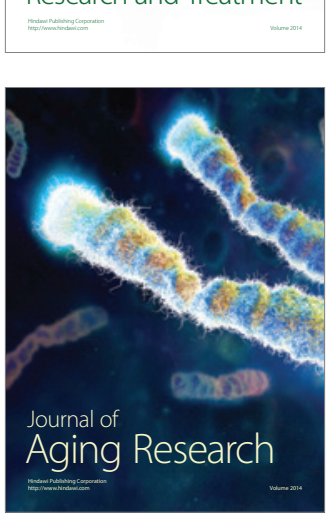
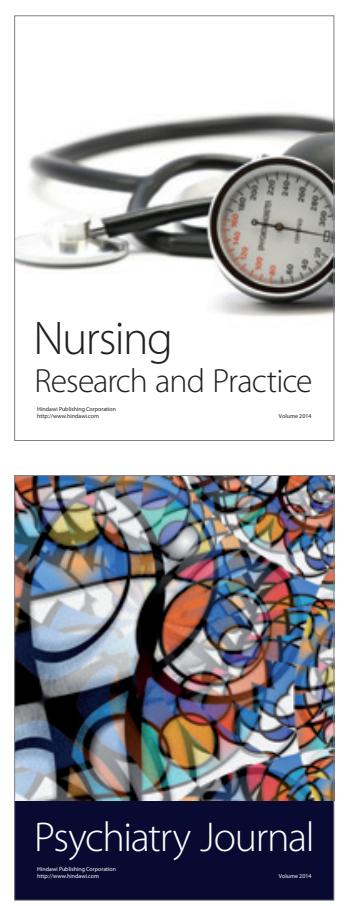
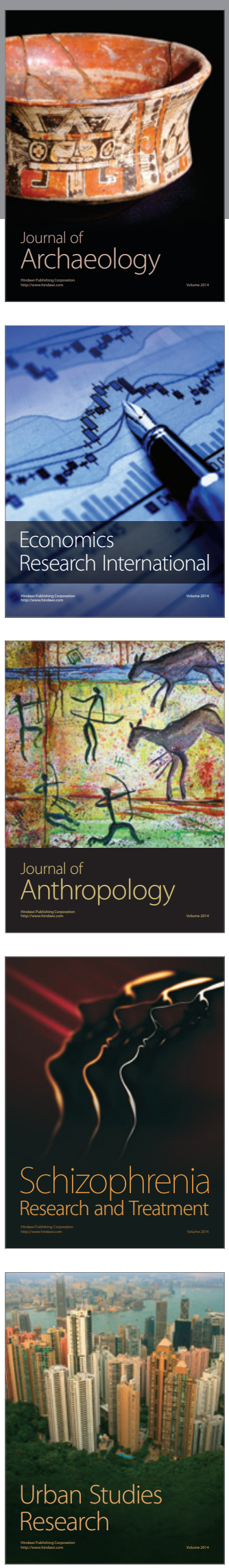